\title{
CD36/Sirtuin 1 Axis Impairment Contributes to Hepatic Steatosis in ACE2-Deficient Mice
}

\author{
Valéria Nunes-Souza, ${ }^{1,2,3,4}$ Natalia Alenina, ${ }^{1,3,5}$ Fatimunnisa Qadri, ${ }^{1}$ Josef M. Penninger, ${ }^{6}$ \\ Robson Augusto S. Santos, ${ }^{3,5}$ Michael Bader, ${ }^{1,3,5,7,8,9}$ and Luiza A. Rabelo ${ }^{1,2,3}$ \\ ${ }^{1}$ Max Delbrück Center for Molecular Medicine, Berlin, Germany \\ ${ }^{2}$ Laboratório de Reatividade Cardiovascular (LRC), Núcleo de Síndrome Metabólica, Universidade Federal de Alagoas, Maceió, Brazil \\ ${ }^{3}$ National Institute of Science and Technology in Nano-Biopharmaceutics (N-BIOFAR), Belo Horizonte, Brazil \\ ${ }^{4}$ Departamento de Fisiologia e Farmacologia, Centro de Biociências (CB), Universidade Federal de Pernambuco, Recife, Brazil \\ ${ }^{5}$ Universidade Federal de Minas Gerais, Belo Horizonte, Brazil \\ ${ }^{6}$ Institute of Molecular Biotechnology of the Austrian Academy of Sciences, Vienna, Austria \\ ${ }^{7}$ Charité-University Medicine Berlin, Berlin, Germany \\ ${ }^{8}$ Institute for Biology, University of Lübeck, Lübeck, Germany \\ ${ }^{9}$ German Center for Cardiovascular Research (DZHK), Berlin, Germany
}

Correspondence should be addressed to Natalia Alenina; alenina@mdc-berlin.de and Luiza A. Rabelo; luizaa.rabelo@gmail.com

Received 9 July 2016; Revised 10 October 2016; Accepted 19 October 2016

Academic Editor: Swaran J. S. Flora

Copyright (C) 2016 Valéria Nunes-Souza et al. This is an open access article distributed under the Creative Commons Attribution License, which permits unrestricted use, distribution, and reproduction in any medium, provided the original work is properly cited.

Background and Aims. Angiotensin converting enzyme 2 (ACE2) is an important component of the renin-angiotensin system. Since angiotensin peptides have been shown to be involved in hepatic steatosis, we aimed to evaluate the hepatic lipid profile in ACE2deficient $\left(\mathrm{ACE}^{-/ \mathrm{y}}\right)$ mice. Methods. Male C57BL/6 and ACE2 ${ }^{-/ \mathrm{y}}$ mice were analyzed at the age of 3 and 6 months for alterations in the lipid profiles of plasma, faeces, and liver and for hepatic steatosis. Results. ACE2 ${ }^{-/ y}$ mice showed lower body weight and white adipose tissue at all ages investigated. Moreover, these mice had lower levels of cholesterol, triglycerides, and nonesterified fatty acids in plasma. Strikingly, ACE2 ${ }^{-/ y}$ mice showed high deposition of lipids in the liver. Expression of CD36, a protein involved in the uptake of triglycerides in liver, was increased in ACE2 ${ }^{-/ y}$ mice. Concurrently, these mice exhibited an increase in hepatic oxidative stress, evidenced by increased lipid peroxidation and expression of uncoupling protein 2, and downregulation of sirtuin 1. ACE2 $2^{-/ y}$ mice also showed impairments in glucose metabolism and insulin signaling in the liver. Conclusions. Deletion of ACE2 causes CD36/sirtuin 1 axis impairment and thereby interferes with lipid homeostasis, leading to lipodystrophy and steatosis.

\section{Introduction}

Nonalcoholic fatty liver disease (NAFLD), a metabolic disorder of increasing clinical importance with different pathological presentations varying from initial hepatic steatosis, through nonalcoholic steatohepatitis, to fibrosis and cirrhosis, has been considered a novel component of the metabolic syndrome (MetS) $[1,2]$. MetS is characterized by a cluster of cardiovascular and metabolic disorders, including central obesity, insulin resistance, glucose intolerance, dyslipidemia, and hypertension $[1,2]$. Emerging evidence indicates that the renin-angiotensin system (RAS) plays an important role in the pathogenesis of MetS and NAFLD [3-6]. The "classical arm" (angiotensin converting enzyme/angiotensin II/AT1 receptor [ACE/AngII/AT1]) promotes the disease [46], whereas the "protective arm" (angiotensin converting enzyme 2/angiotensin-(1-7)/Mas receptor [ACE2/Ang-(17)/Mas]) counteracts it $[3,7,8]$.

ACE acts on angiotensin I to form the AngII, a molecule which constricts vessels after binding to the AT1 receptor in arterioles [9, 10]. Beyond that, AngII has other functions in the cardiovascular system that promote elevated blood pressure, such as increased release of aldosterone and vasopressin, which increase sodium and water reabsorption, 
respectively, in the renal distal tubules [11]. Therefore, ACE2 is an important enzyme that negatively regulates the RAS, through reduction of AngII and increase of Ang-(1-7), a vasodilator molecule, conferring ACE2 a protective role in cardiovascular diseases $[10,11]$.

Metabolic studies demonstrated an important role of the ACE2/Ang-(1-7)/Mas pathway in the maintenance of homeostasis $[3,8,12,13]$. Mice deficient for Mas presented dyslipidemia and hyperglycemia [12]. Moreover, rats overexpressing Ang-(1-7) showed an improvement in glucose tolerance and insulin sensitivity and also exhibited decreased triglycerides, cholesterol, and abdominal fat mass [8]. Treatment of diabetic rats with an oral formulation of Ang-(1-7) resulted in drastic reductions in glycemia and an increase in insulin sensitivity, also implying insulin resistance under high fat conditions [14]. Interestingly, ACE2 is not only a protease which metabolizes peptides, such as AngII, apelin, and des$\mathrm{Arg}^{9}$-bradykinin [15], but is also involved in the resorption of large amino acids from the gut $[16,17]$. In this regard, ACE2 deletion leads to defects in amino acid uptake and intestinal inflammation, but effects on lipid metabolism have not yet been reported.

AngII has been shown to cause NAFLD [18], whereas Ang-(1-7) elicits opposite effects [3]. Accordingly, both ACE inhibitors and AT1 antagonists protect from fatty liver and fibrosis [18], recombinant ACE2 has beneficial effects on hepatic fibrosis in mice [19], and during the preparation of this manuscript, Cao and collaborators [20] showed that ACE2/Ang-(1-7)/Mas axis may reduce liver lipid accumulation. On the other hand, the underlying mechanisms are not yet well understood but, of the many factors that stimulate this process, redox balance seems to be one of the most important in the liver [21, 22].

Reactive oxygen species (ROS), such as nitric oxide ( $\left.{ }^{\circ} \mathrm{NO}\right)$ superoxide anion $\left({ }^{\circ} \mathrm{O}_{2}{ }^{-}\right)$and hydrogen peroxide $\left(\mathrm{H}_{2} \mathrm{O}_{2}\right)$, are crucial mediators of angiotensin peptide actions [10], since AngII promotes their generation [23] and Ang-(1-7) reduces oxidative stress [10]. ROS are chronically elevated in NAFLD and contribute to the pathogenesis of the disease [21, 22]. However, it is still unknown whether ACE2 plays a role in this liver disorder or whether ACE2 deletion interferes with regulation of key factors of lipid metabolism, such as fatty acid translocase, also called cluster of differentiation 36 (CD36), peroxisome proliferator-activated receptor $\gamma$ $(\operatorname{PPAR} \gamma)$, adipocyte protein $2(\mathrm{aP} 2)$, fatty acid synthase (FAS), and sirtuin 1 , as well as of key moderators of ROS production in hepatic metabolism, such as uncoupling protein type 2 (UCP2). Taking in consideration the important role of angiotensins and ROS in the development of NAFLD [21, 22], we aimed to investigate the hepatic lipid profile in ACE2-deficient mice in which the relative abundance of AngII and Ang-(1-7) is distorted. Indeed, we found that the deletion of ACE2 causes hepatic steatosis accompanied by an impairment of the CD36/sirtuin 1 axis, insulin signaling, and glucose metabolism in the liver. These results reveal a central role of ACE2 in lipid homeostasis, preventing lipodystrophy probably by decreasing the levels of AngII and/or increasing Ang-(1-7) in the liver.

\section{Methods}

2.1. Animals and Experimental Procedures. C57BL/6 (WT) and ACE2-deficient (ACE2 $2^{-/ y}$ ) male mice on $\mathrm{C} 57 \mathrm{BL} / 6$ genetic background [9] at 3 and 6 months of age were used in this study under standard diet $(10 \% \mathrm{kcal}$ from fat) from $\mathrm{SSNIFF}^{\circledR}$ (Soest, Germany). The mice were kept in a 12hour light/dark cycle, with controlled humidity and temperature environment and fed ad libitum. All experiments were approved by the "Landesamt für Gesundheit und Soziales" (LAGeSo; Berlin) and performed in accordance with the "Guide for the Care and Use of Laboratory Animals" (NIH publication 86-23, 1996).

2.2. Euthanasia and Organ Collection. After intraperitoneal (i.p) anesthesia using a xylazine/ketamine solution (10/110, $\mathrm{mg} \cdot \mathrm{kg}^{-1}$ ), $12 \mathrm{~h}$-fasted animals were euthanized by exsanguination through cardiac puncture of the right ventricle. The whole blood was collected and centrifuged $(4,000 \mathrm{rpm}$ for $10 \mathrm{~min}$ ), and the plasma was separated and stored at $-80^{\circ} \mathrm{C}$. The animals were perfused with heparinized saline and, in sequence, the liver and white adipose tissue (WAT) were carefully removed, weighed, immediately frozen in dry ice and stored at $-80^{\circ} \mathrm{C}$ until quantitative PCR, western blot and the other analyses were performed. WAT index was calculated using the following formula: WAT index (\%) = $\{($ epididymal fat + perirenal fat $) /($ body weight $)\} * 100$.

2.3. Biochemical Analyses. Nonesterified fatty acid (NEFA) kit was used to measure plasma and liver NEFA concentrations (Wako Chemicals $\mathrm{GmbH}^{\circledR}$, Neuss, Germany). The total cholesterol (TCOL) and triglycerides (TG) levels were assayed with commercials kits (Labtest ${ }^{\circledR}$, Belo Horizonte, Brazil), following the manufacturers' instructions with adaptations for microplates. All measurements were performed with a TECAN ${ }^{\circledR}$ Infinite 200 PRO plate reader (Männedorf, Switzerland).

2.4. Evaluation of Liver Injury. Liver injury (the degree of hepatocellular damage) was assessed by measuring the enzymatic activities of alanine aminotransferase (ALT) and aspartate aminotransferase (AST) in plasma with commercial kits (Labtest, Belo Horizonte, Brazil).

2.5. Liver and Fecal Lipids Analysis. The total hepatic and fecal lipids were extracted according to a gravimetric standard method [24]. Total lipids were measured by weighing the samples on an analytical balance after extraction, being normalized by the mass of faeces used for extraction. After this, the total lipids were diluted in isopropanol and measured by commercial kits for TCOL, TG (Labtest, Belo Horizonte, Brazil), and NEFA (Wako Chemicals GmbH, Neuss, Germany).

2.6. Liver and WAT Histological Analysis. Fragments of liver and WAT were fixed in $4 \%$ buffered formaldehyde, embedded in paraffin and sectioned at $3 \mu \mathrm{m}$ and $10 \mu \mathrm{m}$, respectively. WAT was stained with H\&E in order to determine adipocyte 
diameters. The lipid deposition in the liver was analyzed indirectly by immunofluorescence staining for adipophilin. In brief, sections were deparaffinized, rehydrated, and boiled in citrate buffer, $\mathrm{pH} \mathrm{7,} \mathrm{for} 20 \mathrm{~min}$ in a vegetable steamer. The sections were incubated with an antibody against adipophilin (1:500, Fitzgerald, Acton, USA) overnight at $4^{\circ} \mathrm{C}$. The sections were then incubated with a secondary antibody conjugated with Cy3 $(1: 300)$ and coverslipped using the mounting medium "Vectashild with DAPI-Hard set" (Vector Lab). The sections were observed under a Keyence ${ }^{\circledR}$ microscope (BZ 9000, Osaka, Japan). Digital photographs were taken from each section; adipocyte diameter and adipophilin expression were quantified using the "BZ II Analyzer" image processing software (Keyence BZ 9000 Software, Osaka, Japan).

2.7. Lipid Peroxidation, Superoxide Dismutase, and Catalase Activity Measurement in the Liver. The hepatic lipid peroxidation was quantified by measuring the ThioBarbituric Acid-Reactive Substances (TBARS), a marker of oxidative stress which was assayed by malondialdehyde (MDA) in liver homogenates as described [25]. Total superoxide dismutase (SOD) activity was assessed with a commercial colorimetric kit (Sigma-Aldrich, Seelze, Germany). Catalase activity was measured according to $\mathrm{Xu}$ et al. [26]. All results were normalized to protein concentration [27].

2.8. Gluconeogenesis. Gluconeogenesis was evaluated by the pyruvate test. It was performed after 16 hours overnight fast. The animals were weighed and blood was collected from the tail vein to measure glucose before the injection of $2 \mathrm{~g}$ sodium pyruvate $\cdot \mathrm{kg}^{-1}$ (i.p) (Sodium Pyruvate, Sigma-Aldrich, Seelze, Germany). After injection, the glucose levels were measured at $15,30,60,90$, and 120 minutes.

2.9. Real Time Quantitative PCR. Total RNA was isolated from liver using Trizol (TRizol ${ }^{\circledR}$ Reagent, Invitrogen, Darmstadt, Germany) and subsequently cleaned using RNeasy Mini kit (Qiagen, Hilden, Germany). RNA concentration was quantified using spectrophotometry (NanoDrop ${ }^{\circledR}$, München, Germany) and $1 \mu \mathrm{g}$ was taken for the synthesis of cDNA using M-MLV Reverse Transcriptase (Invitrogen). The reaction product was amplified using the GoTaq qPCR Master Mix (Promega ${ }^{\circledR}$; Mannheim, Germany) by real time quantitative PCR (ABI 7900HT Real-Time PCR System-Applied Biosystems, Darmstadt, Germany) with gene-specific primers (sequences listed in Table 1; Supplemental Data in Supplementary Material available online at http://dx.doi.org/10.1155/ 2016/6487509). The mRNA expression level was quantified by normalization to the internal reference, GAPDH, using the $2^{-\Delta \Delta \mathrm{Ct}}$ method [28].

2.10. Western Blotting. For Western blotting, proteins were isolated using a lysis buffer (Cell Signaling Technology ${ }^{\circledR}$, Beverly, MA) containing mammalian protease and phosphatase inhibitor cocktail (Roche ${ }^{\circledR}$, Mannheim, Germany) and quantified by Bradford assay [27]. The proteins were separated by electrophoresis, transferred to a polyvinylidene fluoride membrane, which was blocked by incubation in
Odyssey $^{\circledR}$ blocking buffer (Li-COR, Biosciences, Lincoln, USA) for $1 \mathrm{~h}$ at room temperature (RT). Thereafter, the membrane was probed (overnight, $4^{\circ} \mathrm{C}$ ) with one of the following primary antibodies: UCP2 $(1: 500)$, sirtuin $1(1: 1,000), \alpha$-IRS1 (1:1,000), PI3-K (1:500), AKT (1:1,000), phospho-GSK $3 \beta$ $(1: 1,000)$, and GSK $3 \beta(1: 1,000)$ followed by incubation with a secondary antibody for $1 \mathrm{~h}$ at RT. Band intensities were acquired and quantified using the Odyssey infrared imaging system (Li-COR, Biosciences, Lincoln, USA). The membrane was stripped and reprobed with $\beta$-actin $(1: 1,000)$ antibody to obtain an endogenous control for protein quantification.

2.11. Statistical Analysis. Data are expressed as mean \pm standard error of the mean (SEM). Student's $t$-test was performed for the between-group comparisons (Graph Pad Prism ${ }^{\circledR}$ 5.0, San Diego, CA, USA). The hepatic gluconeogenesis test was analyzed by two-way ANOVA followed by Bonferroni's posttest. $p<0.05$ was considered statistically significant.

\section{Results}

3.1. ACE2 Deficiency Decreases Body Weight and Changes the Plasma Lipid Profile. To reveal the role of ACE2 in fat metabolism, we evaluated body (BW) and white adipose tissue (WAT) weight and plasma lipid profile in ACE2 $2^{-/ y}$ mice. These animals showed lower BW and WAT index at 3 and 6 months of age compared to WT mice (Figures 1(a) and 1(b)) and a decrease in white adipocyte diameter (Figure 1(c)). The reduction in these parameters was accompanied by decreased lipids in plasma. In 3- and 6 month-old mice, the levels of NEFA in plasma were significantly lower, and at 6 months of age also TCOL and TG were reduced in ACE2 $2^{-/ y}$ mice compared to WT animals (Figures $1(\mathrm{~d})-1(\mathrm{f})$ ).

\subsection{ACE2 Deficiency Leads to Hepatic Steatosis and Oxidative} Stress. As ACE2 ${ }^{-/ y}$ mice develop intestinal dysfunction [16, 17], we investigated whether the missing plasma lipids were released to the faeces in 6-month-old mice. The results showed that there were no significant differences in total lipids, TCOL, TG, and NEFA levels between WT and ACE2 ${ }^{-/ y}$ mice (Figures $1(\mathrm{~g})-1(\mathrm{j})$ ). However, when we investigated ectopic fat deposition, we identified lipid accumulation in the liver. Immunofluorescence staining for adipophilin, a lipid droplet-associated protein, showed a higher fat deposition in $\mathrm{ACE} 2^{-/ \mathrm{y}}$ mice at 6 months of age compared to WT (Figures 2(a) and 2(b)). These data indicate that ACE2 $2^{-/ y}$ mice present a steatotic state.

Although these animals showed no difference in relative liver weight (Figure 2(c)), they stored increased levels of TCOL, TG, and NEFA in the liver at the age of 3 months and of TG and NEFA at the age of 6 months compared to WT (Figures 2(d)-2(f)). Plasma ALT was significantly increased in $\mathrm{ACE} 2^{-/ \mathrm{y}}$ mice at both ages (Figure 2(g)), and plasma AST was also significantly increased in 6-month-old ACE2 $2^{-/ y}$ mice (Figure 2(h)), confirming liver injury in these animals.

Expression analysis of genes, involved in lipid metabolism in the liver, showed that $\mathrm{ACE} 2^{-/ y}$ mice have significantly 


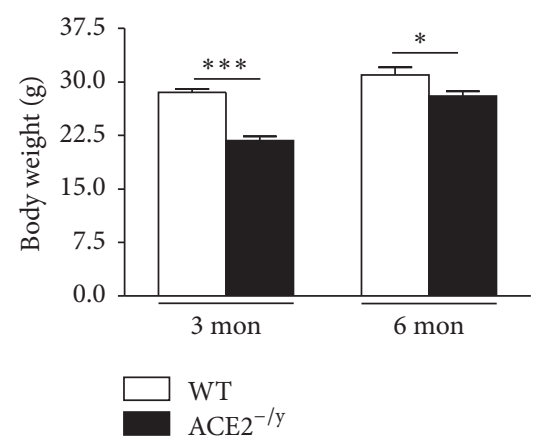

(a)

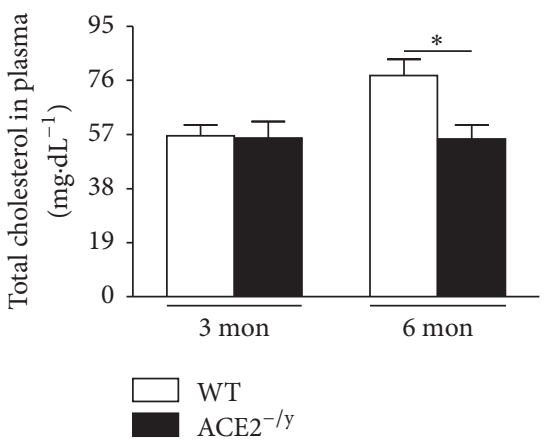

(d)

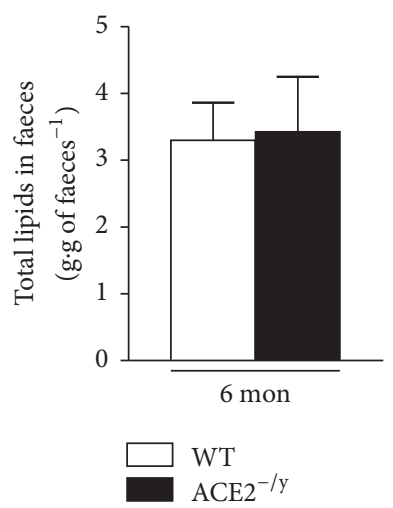

(g)

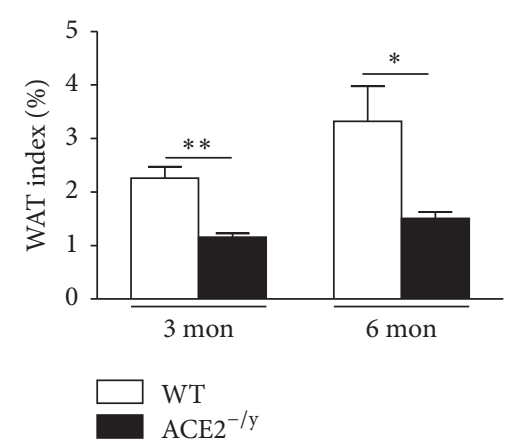

(b)

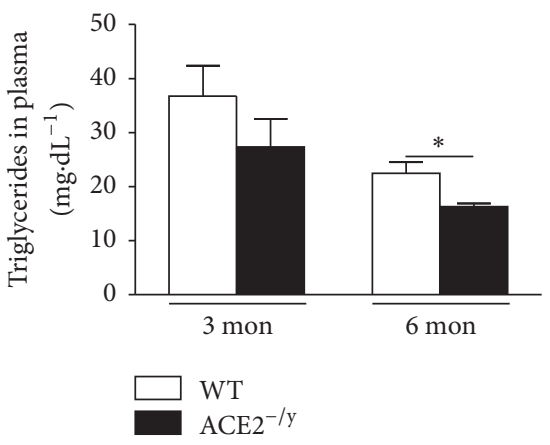

(e)

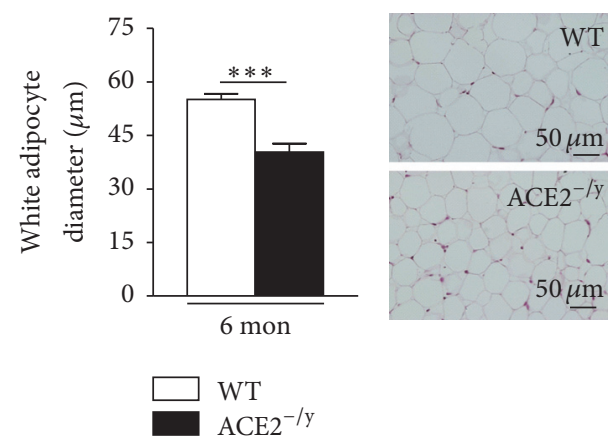

(c)

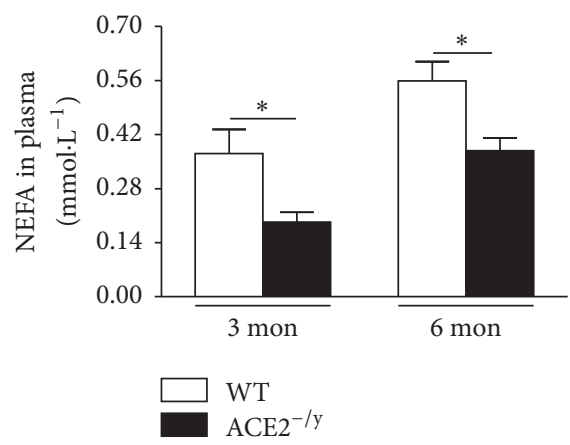

(f)

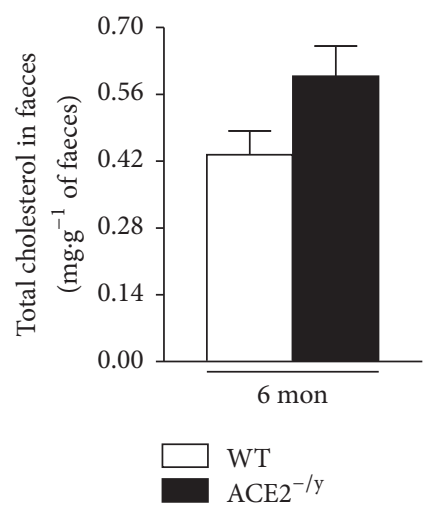

(h)

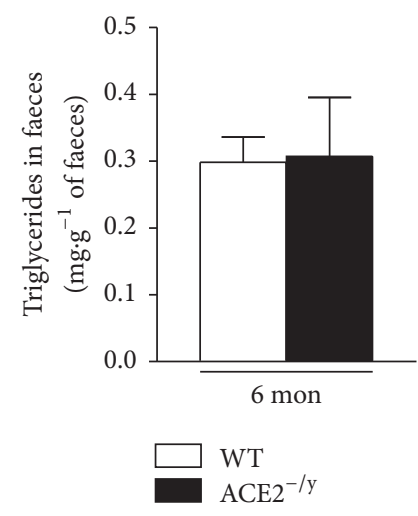

(i)

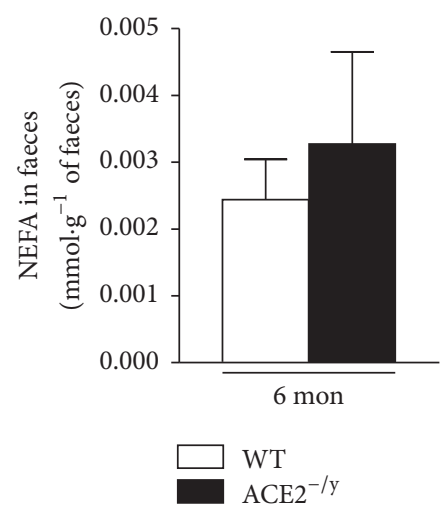

(j)

FIGURE 1: Body weight, WAT index and lipid profile in ACE2 ${ }^{-/ y}$ mice. (a) Body weight (g); (b) WAT index (\%) of WT and ACE2 $2^{-/ y}$ mice at the age of 3 and 6 months; (c) white adipocyte diameter $(\mu \mathrm{m})$; (d) total cholesterol $\left(\mathrm{mg}^{\circ} \cdot \mathrm{dL}^{-1}\right)$, (e) triglycerides, $\left(\mathrm{mg} \cdot \mathrm{dL}^{-1}\right)$, (f) nonesterified fatty acids (NEFA) (mmol. $\left.\mathrm{L}^{-1}\right)$ in plasma of WT and ACE2 ${ }^{-/ y}$ mice at the age of 3 and 6 months; (g) total lipids (g. $\mathrm{g}^{-1}$ of faeces), (h) total cholesterol (mg.g ${ }^{-1}$ of faeces), (i) triglycerides (mg.g of faeces ${ }^{-1}$ ), and (j) NEFA (mmol.g of faeces ${ }^{-1}$ ) in faeces of WT and ACE2 $2^{-/ y}$ mice at the age of 6 months. Each bar graph represents the mean \pm SEM. Student's $t$ test: ${ }^{*} p<0.05 ;{ }^{* *} p<0.01 ;{ }^{* * *} p<0.001$.

more mRNA for CD36, but the levels of mRNA for PPAR $\gamma$, aP2, and FAS in the liver were not different between $\mathrm{ACE} 2^{-/ y}$ and WT mice (Figure 3).

$\mathrm{ACE} 2^{-/ y}$ mice showed increased hepatic lipid peroxidation at the age of 3 , but not 6 months (Figure 4(a)). Next, we analyzed antioxidant enzymes in liver homogenates. SOD activity showed no difference between $\mathrm{ACE} 2^{-/ y}$ and $\mathrm{WT}$ at the age of 6 months. However, catalase activity was significantly higher in ACE2 ${ }^{-/ y}$ mice compared to WT (Figures 4(b) and 4(c)). In addition, the expression of the $\mathrm{UCP} 2$ was significantly higher in $\mathrm{ACE} 2^{-/ \mathrm{y}}$ mice compared to
WT at mRNA (Figure 4(d)) and protein levels at both ages (Figure 4(e)), suggesting that the steatosis is accompanied by oxidative stress. The levels of sirtuin 1 were significantly decreased in liver of 6 - but not 3-month-old ACE2 ${ }^{-/ y}$ mice compared to WT (Figure 4(f)).

3.3. ACE2 Deficiency Leads to Impaired Insulin Signaling in the Liver. As steatosis is often associated with insulin resistance [2], we investigated glucose metabolism and insulin signaling in the liver of $\mathrm{ACE} 2^{-/ y}$ mice. In this organ, $\mathrm{ACE} 2^{-/ \mathrm{y}}$ mice showed severe impairment in insulin signaling and 

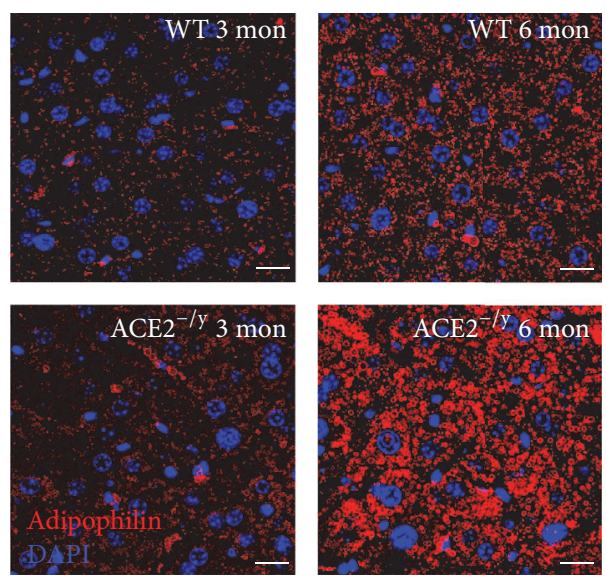

(a)

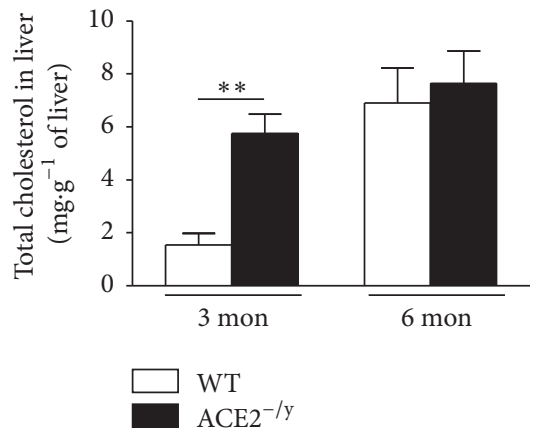

(d)

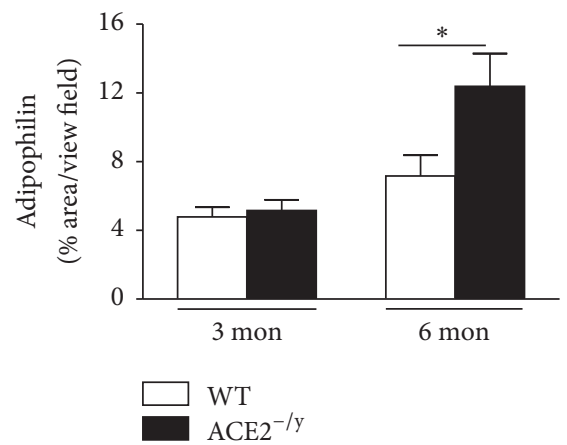

(b)

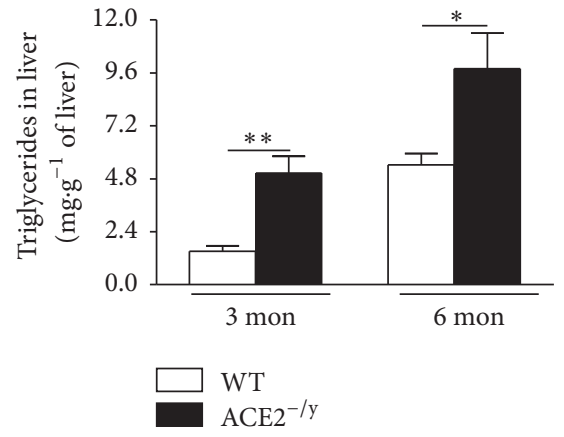

(e)

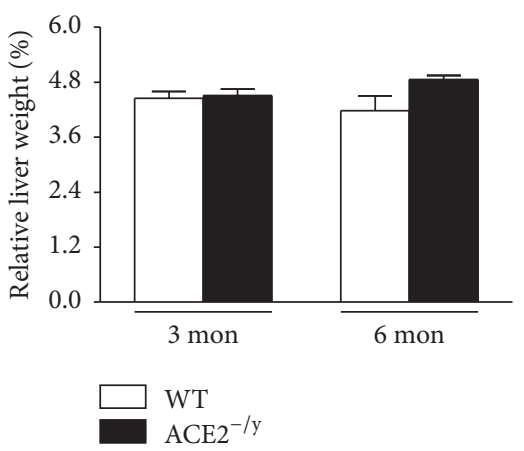

(c)

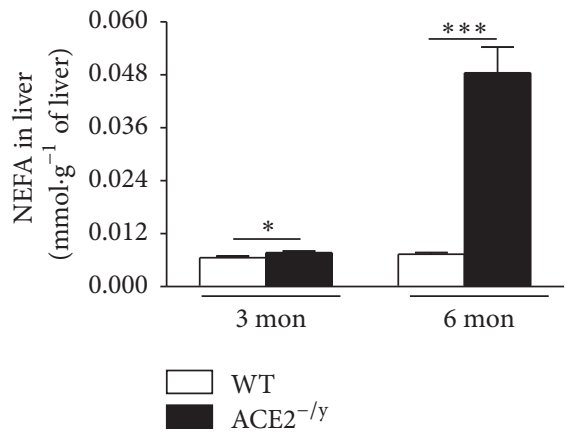

(f)

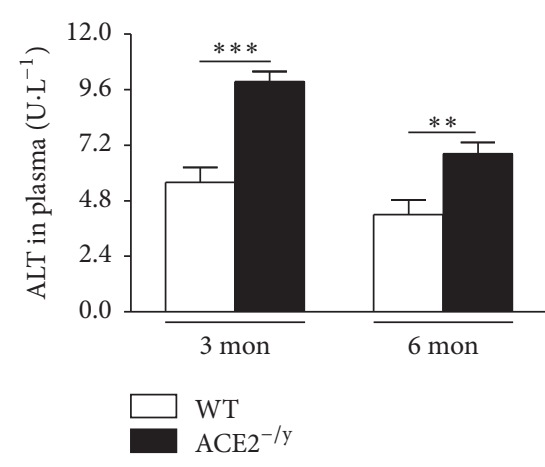

(g)

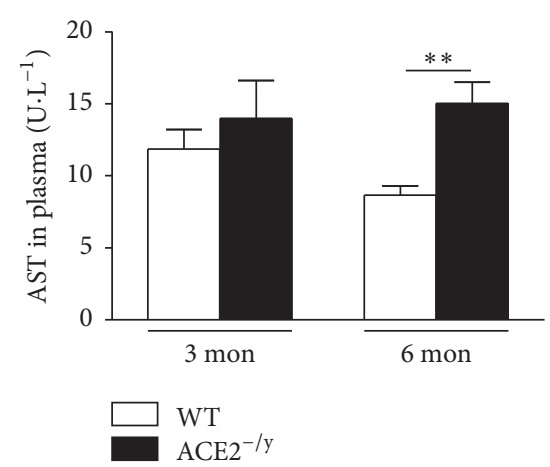

(h)

FIGURE 2: Hepatic steatosis and liver function of ACE2 ${ }^{-/ y}$ mice. (a) Immunofluorescence staining for adipophilin in the liver; (b) adipophilin

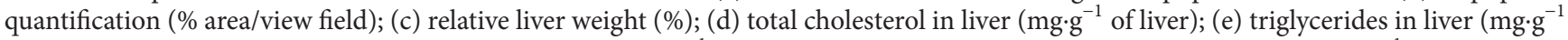
of liver); (f) nonesterified fatty acids (NEFA) in liver ( $\mathrm{mmol} \cdot \mathrm{g}^{-1}$ of liver); (g) alanine aminotransferase (ALT) in plasma (U. $\mathrm{L}^{-1}$ ); (h) aspartate aminotransferase (AST) in plasma $\left(\mathrm{U} \cdot \mathrm{L}^{-1}\right)$ of WT and ACE2 ${ }^{-/ y}$ mice at the age of 3 and 6 months. Each bar graph represents the mean \pm SEM. Student's $t$ test: ${ }^{*} p<0.05 ;^{* *} p<0.01 ;{ }^{* * *} p<0.001$.

glucose handling. Whereas the hepatic capacity of glucose production from pyruvate was not altered in these mice (Figure 5(a)), several genes involved in glucose metabolism were dysregulated. $\mathrm{ACE} 2^{-/ y}$ mice presented a reduction in the relative expression of glucokinase (GCK) and of glucose transporter type 2 (GLUT2) and increased levels of expression of glucose 6-phosphatase (G6Pase) and phosphoenolpyruvate carboxykinase subtype 2 (PCK2). The other subtype, PCK1, and the insulin receptor were however not differentially expressed between the groups (Figure 5(b)). Moreover, $\mathrm{ACE} 2^{-/ y}$ mice presented a significant decrease in proteins involved in glycolysis, such as insulin receptor substrate-1 ( $\alpha$ IRS-1), phosphatidyl inositol-3 kinase (PI3-K), and AKT compared to WT (Figures 5(c)-5(e)). Furthermore, GSK $3 \beta$ and phosphorylated GSK $3 \beta$ were decreased in $\mathrm{ACE} 2^{-/ y}$ mice (Figures $5(\mathrm{f})$ and $5(\mathrm{~g})$ ). However, GSK $3 \beta$ /phosphorylated GSK $3 \beta$ ratio was not different between groups (Figure 5(h)). 


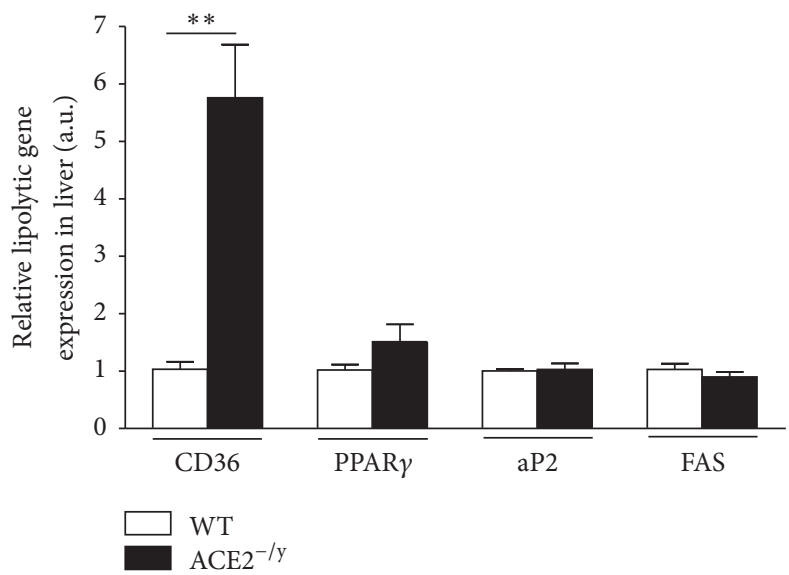

FIGURE 3: Relative expression of genes involved in the lipolytic pathway in the liver. mRNA expression levels (arbitrary units) of fatty acid translocase (CD36), peroxisome proliferator-activated receptor gamma (PPAR $\gamma$ ), adipocyte protein 2 (aP2), and fatty acid synthase (FAS) of WT and ACE2 ${ }^{-/ y}$ mice at the age of 6 months. Each bar graph represents the mean \pm SEM. Student's $t$ test: ${ }^{* *} p<0.01$.

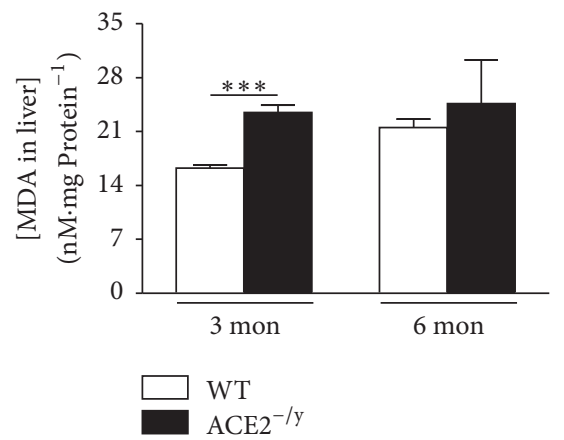

(a)

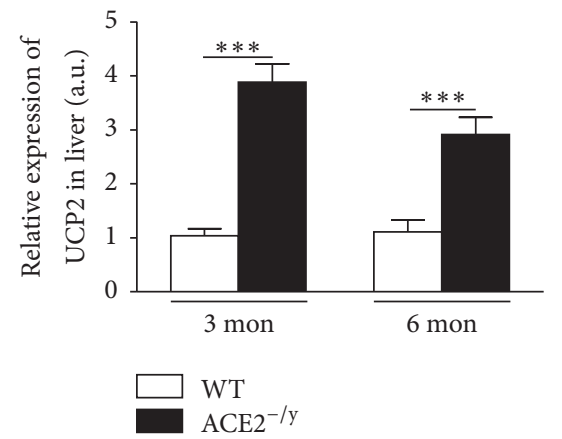

(d)

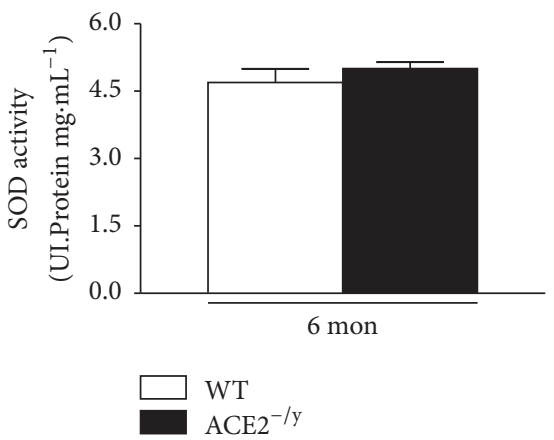

(b)

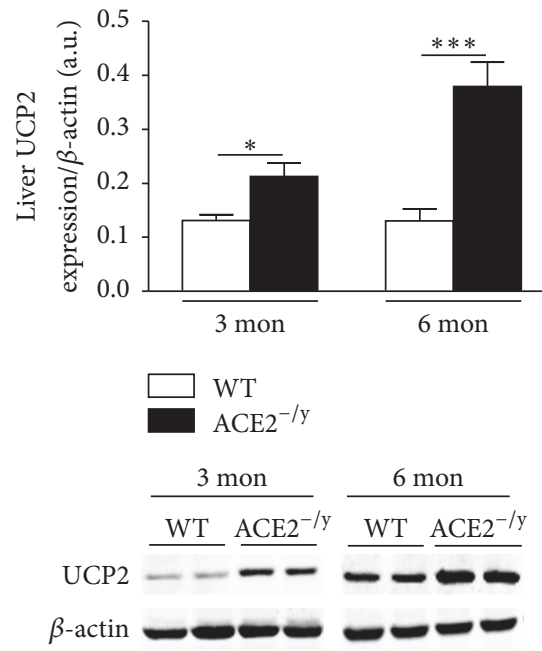

(e)

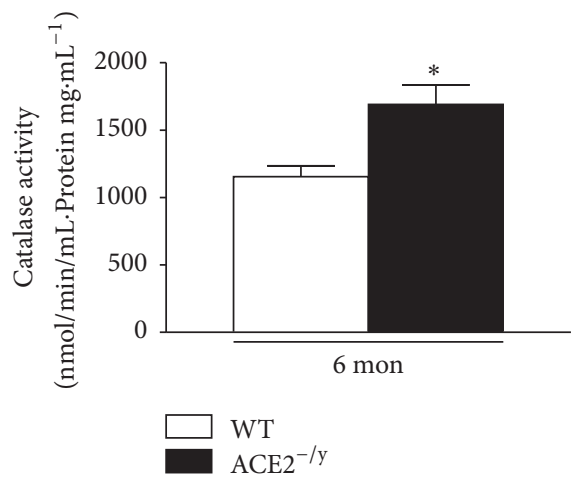

(c)

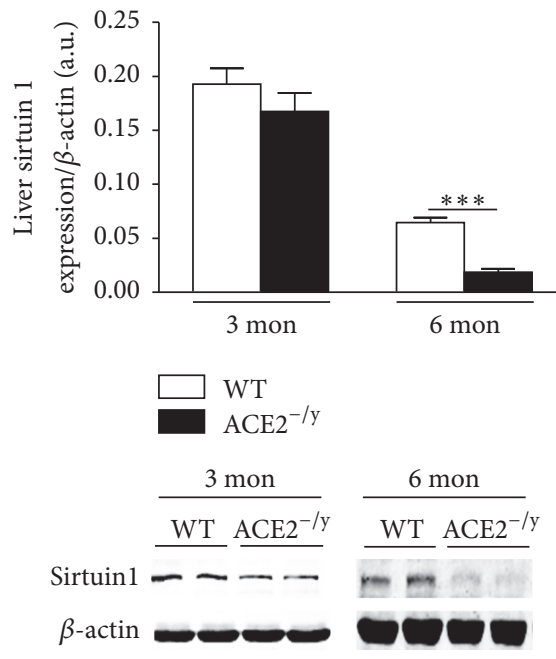

(f)

FIGURE 4: Markers of redox status, antioxidant enzymes, and sirtuin 1 protein expression in liver. (a) Malondialdehyde (MDA) in liver of WT and $\mathrm{ACE} 2^{-/ y}$ mice at the age of 3 and 6 months (nM.mg protein $\left.{ }^{-1}\right)$; (b) superoxide dismutase (SOD) activity in the liver (UI.Protein $\mathrm{mg} \cdot \mathrm{mL}^{-1}$ ); (c) catalase activity in the liver (nmol/min/mL·Protein $\mathrm{mg} \cdot \mathrm{mL}^{-1}$ ) of WT and ACE2 $2^{-/ y}$ mice at the age of 6 months; (d) relative mRNA and (e) protein expression of uncoupling protein 2 (UCP2) in the liver (arbitrary units); (f) sirtuin 1 protein expression in the liver (arbitrary units) of WT and ACE2 $2^{-/ y}$ mice at the age of 3 and 6 months. Each bar graph represents the mean \pm SEM. Student's $t$ test: ${ }^{*} p<0.05 ;{ }^{* * *} p<0.001$. 


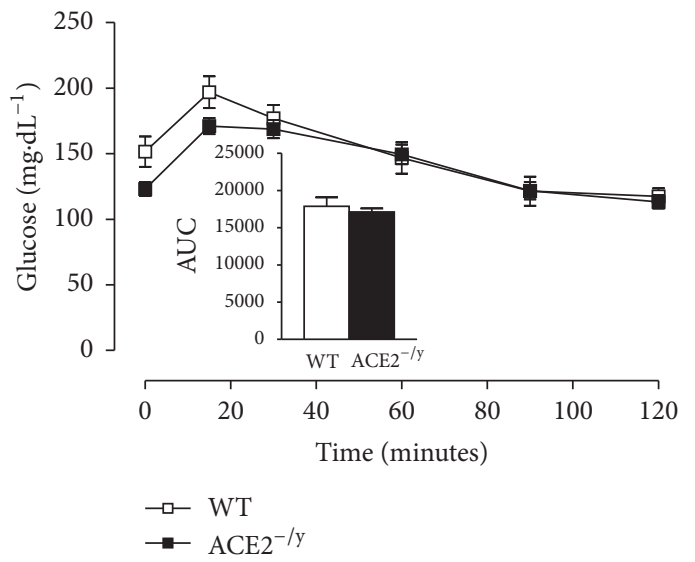

(a)

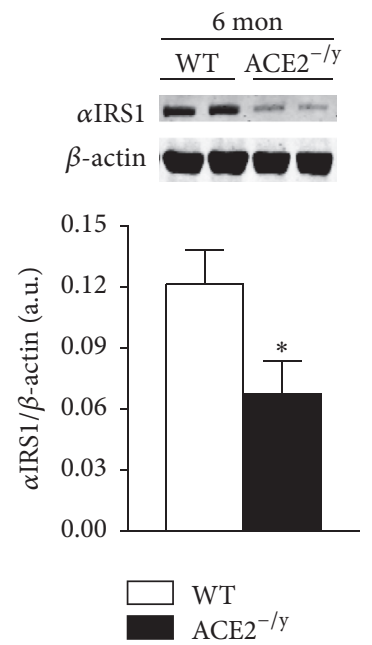

(c)
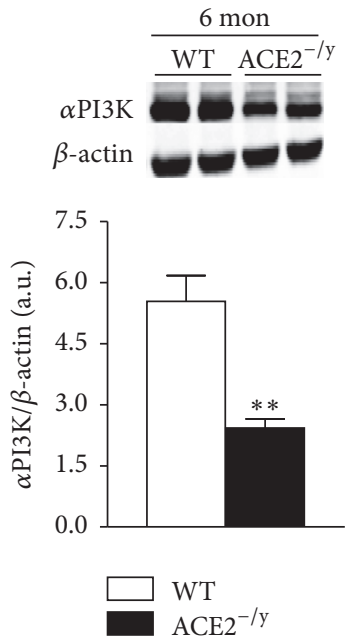

(d)

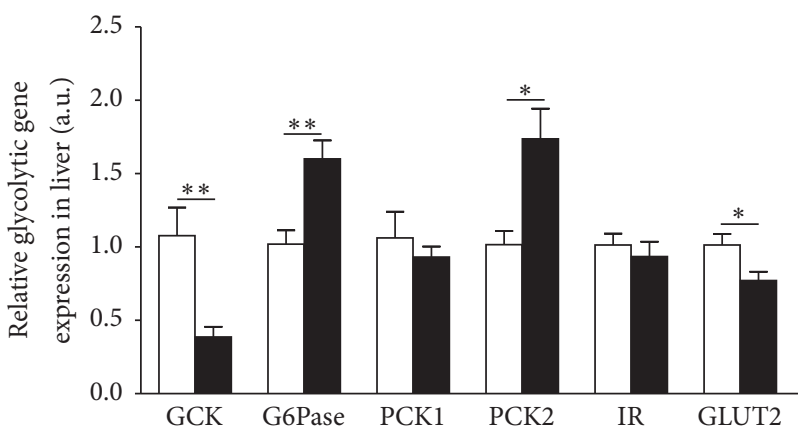

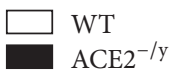

(b)
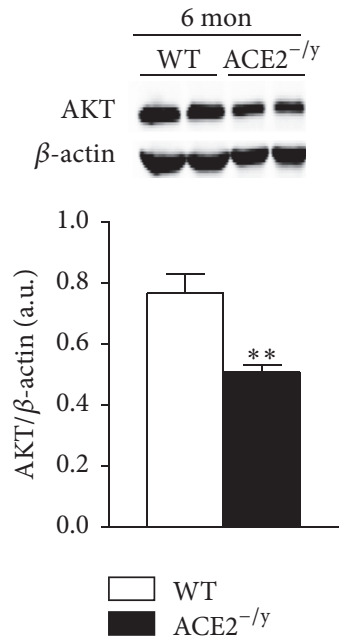

(e)
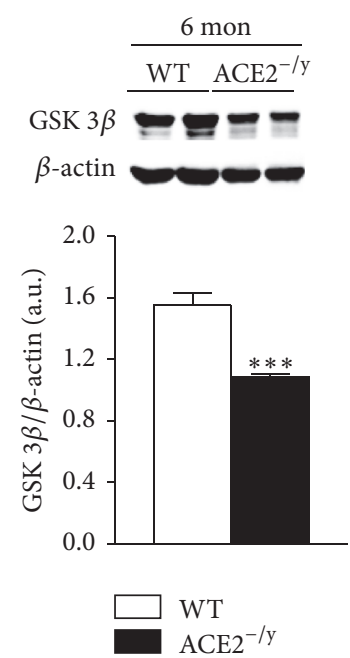

(f)

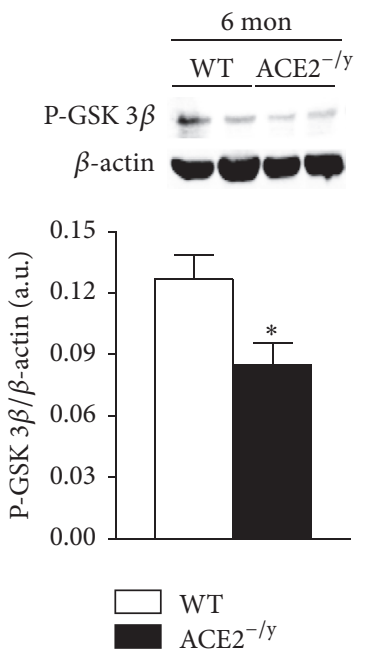

(g)

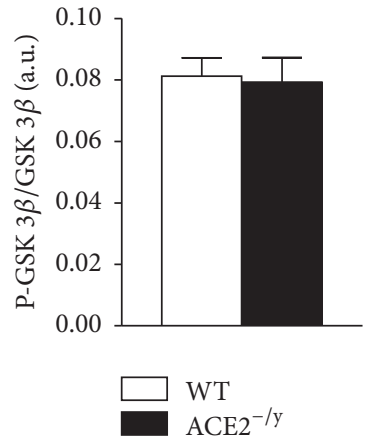

(h)

FIGURE 5: Hepatic glucose metabolism. (a) Evaluation of hepatic gluconeogenesis stimulated by intraperitoneal injection of pyruvate and area under the curve of the test (AUC); (b) relative mRNA expression of glycolytic genes in the liver (glucokinase, GCK; glucose 6-phosphatase, G6Pase; phosphoenolpyruvate carboxykinase 1 and 2, PCK; insulin receptor, IR; and glucose transporter type 2, GLUT2) (arbitrary units); (c) $\alpha$-insulin receptor substrate-1 ( $\alpha$ IRS) protein expression in the liver (arbitrary units); (d) phosphatidyl inositol-3 kinase (PI3-K) protein expression in the liver (arbitrary units); (e) AKT protein expression in the liver (arbitrary units); (f) glycogen synthase kinase (GSK) $3 \beta$ in the liver (arbitrary units); (g) phospho-GSK $3 \beta$ in the liver (arbitrary units); (h) GSK 3 $\beta$ /phospho-GSK $3 \beta$ in the liver (arbitrary units) of WT and ACE2 ${ }^{-/ y}$ mice at the age of 6 months. Data are presented as mean \pm SEM. Student's $t$ test: ${ }^{*} p<0.05 ;{ }^{* *} p<0.01 ;{ }^{* * *} p<0.001$. 


\section{Discussion}

The major findings of the present study are that the deletion of ACE2 causes paradoxical metabolic effects: on the one hand, it results in a markedly diminished BW and WAT. On the other hand, it leads to the development of steatosis and insulin resistance in the liver. Evidence for this disorder includes an increased amount of adipophilin-containing vesicles in hepatocytes (Figures 2(a) and 2(b)), augmented lipids in the liver (Figures 2(d)-2(f)), and an accumulation of liver enzymes in plasma as indication of liver injury (Figures 2(g) and $2(\mathrm{~h})$ ). The decrease of WAT index, adipocyte diameter (Figures 1(b) and 1(c)), and plasma lipids (Figures 1(d)-1(f)) associated with the normal faecal lipid excretion (Figures $1(\mathrm{~g})-1(\mathrm{j})$ ) suggested an increased uptake of fatty acids by the liver as primary cause for the NAFLD observed in $\mathrm{ACE}^{-/ y}$ mice. Indeed, CD36, the fatty acid translocase, is upregulated in mice lacking ACE2 (Figure 3). It has been shown that the upregulation of CD36 in the liver is associated with increased steatosis in NAFLD patients $[29,30]$ and $\mathrm{CD} 36^{-/-}$mice are resistant to alcohol and high carbohydrateinduced hepatic steatosis [31]. Moreover, in mice and humans aging increases CD36 membrane expression in the liver [29], causing increased fat uptake and advancing NAFLD with age. The increase in CD36 may be caused by the decreased expression of sirtuin 1 in $\mathrm{ACE}^{-/ y}$ mice (Figure 4(f)), as it was observed in heterozygous sirtuin 1 deficient animals [32]. In addition, Cao and collaborators [33] showed that the deletion of hepatocyte-specific menin causes steatosis in aging mice by decreasing the levels of sirtuin 1 in the liver and upregulation of $\mathrm{CD} 36$, which demonstrates a metabolic link between CD36 and sirtuin 1. AngII has been shown to downregulate sirtuin 1 in other cell types [34] and Ang-(1-7) exhibit the opposite effect in liver cells [35]. Thus, a downregulation of this translocase can be expected from the imbalance between the two peptides in $\mathrm{ACE} 2^{-/ \mathrm{y}}$ mice. Interestingly, it has recently been shown that sirtuin 1 can vice versa regulate ACE2 expression [36].

Increase in cytosolic fatty acids leads to mitochondrial damage and the production of reactive oxygen species (ROS) [21]. Moreover, hepatic sirtuin 1 deficiency in mice induces oxidative liver damage [37]. Indeed, we observed increased lipid peroxidation and UCP2 expression as oxidative markers also in the liver of $\mathrm{ACE} 2^{-/ y}$ mice suggesting that steatosis is accompanied by elevated oxidative stress in these animals. The high lipid peroxidation observed in the $\mathrm{ACE} 2^{-/ y}$ mice at the age of 3 months is probably due to a high production of $\mathrm{H}_{2} \mathrm{O}_{2}$ in these mice [38]. This could explain the high catalase activity, which degrades $\mathrm{H}_{2} \mathrm{O}_{2}$, in an attempt to combat the elevation of this ROS [38]. UCP2, a mitochondrial anion carrier protein [39], plays a key role as a moderator of ROS production in hepatic metabolism [40, 41]. Accordingly, $\mathrm{UCP}^{-1-}$ mice showed increased ROS formation [42]. In $\mathrm{ACE}^{-/ \mathrm{y}}$ mice, an increase in intracellular lipids in the liver may lead to a mitochondria overload, followed by an increase in ROS production during the $\beta$-oxidation of lipids, which in turn stimulates the expression of UCP2 to combat this imbalance. These data suggest that the increased expression of this uncoupling protein could be an insufficient defense mechanism in the attempt to prevent the progression of steatosis in $\mathrm{ACE} 2^{-/ y}$ mice [43]. We cannot exclude that AngII-induced oxidative stress may be a primary cause of liver steatosis in $\mathrm{ACE} 2^{-/ y}$ mice, which is not compensated by Ang-(1-7) in these animals. Experimental evidence indicates that RAS signaling plays a critical role in the metabolism of fat in the liver $[3,4,7,18,19,44]$. Moreover, Cao and collaborators [20] recently confirmed that $\mathrm{ACE} 2^{-/ y}$ mice present hepatic steatosis, oxidative stress, and inflammation. This report also showed that Ang-(1-7) and ACE2 ameliorated all of these parameters in a liver cell line. The authors attribute the reduction of liver lipid accumulation, induced by ACE2/Ang-(1-7)/Mas axis, partly to the regulation of lipidmetabolizing genes.

As already described in other mouse models and patients [45], the high lipid deposition in the liver of $\mathrm{ACE} 2^{-/ y}$ mice resulted in impaired insulin signaling and glucose metabolism. Although these animals showed normal glucose production from pyruvate, changes in the expression of important genes for glucose metabolism, such as GCK, G6Pase, PCK2, and GLUT2, suggest that as a result of steatosis, glycolysis could be impaired. Furthermore, the decrease in IRS-1, PI3-K, AKT, and GSK3 $\beta$ pathway confirms that insulin signaling is impaired in the liver of $\mathrm{ACE} 2^{-/ y}$ mice. Accordingly, Cao and collaborators [46] showed that the activation of the ACE2/Ang-(1-7)/Mas axis has a beneficial effect on insulin resistance in the liver through reduced oxidative stress in hepatic cells and modulation of the Akt/PI3K/IRS-1/JNK insulin signaling pathway.

ACE-deficient mice show a pronounced increase in expression of key genes involved in lipolysis and fatty acid oxidation in the liver, such as lipoprotein lipase, carnitine palmitoyl transferase, and long-chain acetyl CoA dehydrogenase. This suggests an increase in fatty acid hydrolysis and $\beta$ oxidation, which could prevent an accumulation of lipids in the liver and might be due to the absence of AngII in these knockout animals [6]. On the other hand, ACE2-deficient mice have increased levels of AngII which is known to contribute to the development of steatosis and insulin resistance [45]. AT1 receptor activation leads to steatosis via decreased UCP2 in a rat model with metabolic syndrome [47], and the deletion of AT1 receptor reduces hepatic steatosis [44]. Moreover, it has been shown that the oral treatment with Ang-(1-7) prevents HFD-induced steatosis [7] and that the deletion of Mas in ApoE-deficient mice leads to an increased hepatic lipid content [3]. Taken together, this large body of experimental evidence and our results show that a balanced activity of the two axes of the RAS, ACE/AngII/AT1 and ACE2/Ang-(1-7)/Mas, is essential to metabolize fat for energy maintenance in the liver without inducing steatosis. The observed BW reduction in ACE2-deficient mice confirms the findings of Singer et al. [17], who link it to the defective amino acid absorption in the gut of these animals. However, the reduction in WAT by the mechanism described in our study may also contribute to this phenotype. Future studies have to validate the proposed mechanisms by which angiotensin peptides regulate lipid metabolism and hepatic oxidative stress. 


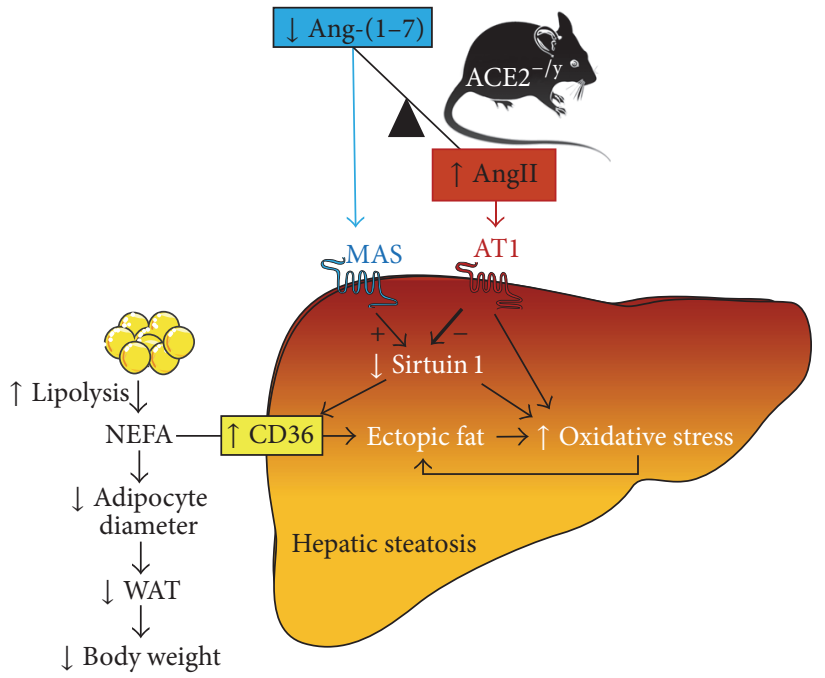

Figure 6: Proposed mechanism of hepatic steatosis in ACE2 ${ }^{-/ y}$ mice. ACE2 deletion causes an imbalance between Ang-(1-7) and AngII with higher levels of the latter. Since Ang-(1-7) via Mas stimulates and AngII via the AT1 receptor inhibits sirtuin 1 expression, this regulatory factor is downregulated. This leads to upregulation of the fatty acid translocase, CD36, and an increased uptake of nonesterified fatty acids (NEFA) into hepatocytes causing ectopic fat deposition and oxidative stress in the liver. Oxidative stress is augmented by direct effects of the decreased sirtuin 1 and the increased AT1-signalling on the formation of reactive oxygen species. In the blood, NEFAs are decreased leading to shrinking adipocytes and fat pads, as well as a drop in body weight.

In sum, ACE2 deletion causes CD36/sirtuin 1 axis impairment and thereby contributes to the fat deposition in the liver leading to NAFLD, oxidative stress, and impaired insulin signaling (summarized in Figure 6). Therefore, ACE2deficient mice provide a suitable model for assessing the pathophysiological relevance of NAFLD and represent an excellent tool to investigate new therapeutic strategies for MetS as well as associating disorders.

\section{Abbreviations}

ACE: Angiotensin converting enzyme

ACE2: $\quad$ Angiotensin converting enzyme 2

ALT: $\quad$ Alanine aminotransferase

Ang-(1-7): Angiotensin-(1-7)

AngII: Angiotensin II

aP2: $\quad$ Adipocyte protein 2 (fatty acid binding protein)

AST: $\quad$ Aspartate aminotransferase

AT1: $\quad$ AT1 receptor

BW: $\quad$ Body weight

CD36: Cluster of differentiation 36 (fatty acid translocase)

FAS: $\quad$ Fatty acid synthase

G6Pase: Glucose 6-phosphatase

GAPDH: Glyceraldehyde 3-phosphate dehydrogenase

GCK: Glucokinase

GLUT2: Glucose transporter type 2

GSK: Glycogen synthase kinase

$\mathrm{H}_{2} \mathrm{O}_{2}$ : Hydrogen peroxide

H\&E: $\quad$ Hematoxylin and eosin

HFD: $\quad$ High fat diet

IR: Insulin receptor
IRS: Insulin receptor substrate

MDA: Malondialdehyde

MetS: Metabolic syndrome

NAFLD: Nonalcoholic fatty liver disease

NEFA: Nonesterified fatty acids

PCK1: Phosphoenolpyruvate carboxykinase 1

PCK2: Phosphoenolpyruvate carboxykinase 2

PI3-K: Phosphatidyl inositol-3 kinase

PPAR $\gamma$ : Peroxisome proliferator-activated receptor

RAS: $\quad \begin{aligned} & \gamma \\ & \text { Renin-angiotensin system }\end{aligned}$

ROS: Reactive oxygen species

SOD: Superoxide dismutase

TBARS: ThioBarbituric Acid-Reactive Substances

TCOL: Total cholesterol

TG: Triglycerides

UCP2: Uncoupling protein 2

WAT: White adipose tissue.

\section{Competing Interests}

The authors have declared that no conflict of interests exists.

\section{Authors' Contributions}

Valéria Nunes-Souza, Natalia Alenina, Michael Bader, and Luiza A. Rabelo conceived and designed the experiments. Valéria Nunes-Souza, Natalia Alenina, Fatimunnisa Qadri, and Luiza A. Rabelo performed the experiments. Valéria Nunes-Souza, Fatimunnisa Qadri, and Luiza A. Rabelo analyzed the data. Valéria Nunes-Souza, Fatimunnisa Qadri, Michael Bader, and Luiza A. Rabelo interpreted the results of experiments. Josef M. Penninger, Michael Bader, Natalia 
Alenina, Robson Augusto S. Santos, and Luiza A. Rabelo contributed with reagents/materials/animals/analysis tools. Valéria Nunes-Souza and Luiza A. Rabelo wrote the paper. Valéria Nunes-Souza, Fatimunnisa Qadri, and Luiza A. Rabelo prepared figures. Luiza A. Rabelo, Michael Bader, Natalia Alenina, and Robson Augusto S. Santos edited and revised the manuscript.

\section{Acknowledgments}

The authors thank Sabine Grueger and Susanne da Costa Gonçalves for their technical assistance in animal care, Mihail Todiras for helpful discussions, and Lucas José Sá da Fonseca and Iris Apostel-Krause for their support in the organization of the manuscript. Valéria Nunes-Souza was supported by the Fellowship DAAD/CNPq/CAPES-Brazil (Grant 246794/2012-7). Luiza A. Rabelo received a Postdoctoral Fellowship from CNPq-Brazil (Grant 202139/2010-7). Natalia Alenina was supported by CNPq (Grant BJT 407352), and Robson Augusto S. Santos and Natalia Alenina were supported by DAAD-CAPES exchange program PROBRAL. Josef M. Penninger was supported by an Advanced ERC grants and the Austrian Academy of Sciences.

\section{References}

[1] K. G. M. M. Alberti, R. H. Eckel, S. M. Grundy et al., "Harmonizing the metabolic syndrome: A joint interim statement of the international diabetes federation task force on epidemiology and prevention; National heart, lung, and blood institute; American heart association; World heart federation; International atherosclerosis society; And international association for the study of obesity," Circulation, vol. 120, no. 16, pp. 1640-1645, 2009.

[2] M. den Boer, P. J. Voshol, F. Kuipers, L. M. Havekes, and J. A. Romijn, "Hepatic steatosis: a mediator of the metabolic syndrome. Lessons from animal models," Arteriosclerosis, Thrombosis, and Vascular Biology, vol. 24, no. 4, pp. 644-649, 2004.

[3] A. R. Silva, E. C. Aguilar, J. I. Alvarez-Leite et al., "Mas receptor deficiency is associated with worsening of lipid profile and severe hepatic steatosis in ApoE-knockout mice," American Journal of Physiology-Regulatory Integrative and Comparative Physiology, vol. 305, no. 11, pp. R1323-R1330, 2013.

[4] Y. Wei, S. E. Clark, E. M. Morris et al., "Angiotensin II-induced non-alcoholic fatty liver disease is mediated by oxidative stress in transgenic TG(mRen2)27(Ren2) rats," Journal of Hepatology, vol. 49, no. 3, pp. 417-428, 2008.

[5] A. P. Jayasooriya, M. L. Mathai, L. L. Walker et al., "Mice lacking angiotensin-converting enzyme have increased energy expenditure, with reduced fat mass and improved glucose clearance," Proceedings of the National Academy of Sciences of the United States of America, vol. 105, no. 18, pp. 6531-6536, 2008.

[6] E. Matthew Morris, J. A. Fletcher, J. P. Thyfault, and R. S. Rector, "The role of angiotensin II in nonalcoholic steatohepatitis," Molecular and Cellular Endocrinology, vol. 378, no. 1-2, pp. 2940, 2013.

[7] J. D. Feltenberger, J. M. O. Andrade, A. Paraíso et al., "Oral formulation of angiotensin-(1-7) improves lipid metabolism and prevents high-fat diet-induced hepatic steatosis and inflammation in mice," Hypertension, vol. 62, no. 2, pp. 324-330, 2013.
[8] S. H. S. Santos, J. F. Braga, E. G. Mario et al., "Improved lipid and glucose metabolism in transgenic rats with increased circulating angiotensin-(1-7)," Arteriosclerosis, Thrombosis, and Vascular Biology, vol. 30, no. 5, pp. 953-961, 2010.

[9] M. A. Crackower, R. Sarao, G. Y. Oudit et al., "Angiotensinconverting enzyme 2 is an essential regulator of heart function," Nature, vol. 417, no. 6891, pp. 822-828, 2002.

[10] L. A. Rabelo, N. Alenina, and M. Bader, "ACE2-angiotensin(1-7)-Mas axis and oxidative stress in cardiovascular disease," Hypertension Research, vol. 34, no. 2, pp. 154-160, 2011.

[11] M. Bader, "Tissue renin-angiotensin-aldosterone systems: targets for pharmacological therapy," Annual Review of Pharmacology and Toxicology, vol. 50, pp. 439-465, 2010.

[12] S. H. S. Santos, L. R. Fernandes, É. G. Mario et al., "Mas deficiency in FVB/ $\mathrm{N}$ mice produces marked changes in lipid and glycemic metabolism," Diabetes, vol. 57, no. 2, pp. 340-347, 2008.

[13] M. Takeda, K. Yamamoto, Y. Takemura et al., "Loss of ACE2 exaggerates high-calorie diet-induced insulin resistance by reduction of GLUT4 in mice," Diabetes, vol. 62, no. 1, pp. 223233, 2013.

[14] S. H. S. Santos, J. F. Giani, V. Burghi et al., "Oral administration of angiotensin-(1-7) ameliorates type 2 diabetes in rats," Journal of Molecular Medicine, vol. 92, no. 3, pp. 255-265, 2014.

[15] C. Vickers, P. Hales, V. Kaushik et al., "Hydrolysis of biological peptides by human angiotensin-converting enzyme-related carboxypeptidase," The Journal of Biological Chemistry, vol. 277, no. 17, pp. 14838-14843, 2002.

[16] T. Hashimoto, T. Perlot, A. Rehman et al., "ACE2 links amino acid malnutrition to microbial ecology and intestinal inflammation," Nature, vol. 487, no. 7408, pp. 477-481, 2012.

[17] D. Singer, S. M. R. Camargo, T. Ramadan et al., "Defective intestinal amino acid absorption in Ace2 null mice," American Journal of Physiology-Gastrointestinal and Liver Physiology, vol. 303, no. 6, pp. G686-G695, 2012.

[18] J. E. Toblli, M. C. Mũoz, G. Cao, J. Mella, L. Pereyra, and R. Mastai, "ACE inhibition and AT1 receptor blockade prevent fatty liver and fibrosis in obese zucker rats," Obesity, vol. 16, no. 4, pp. 770-776, 2008.

[19] C. H. Österreicher, K. Taura, S. De Minicis et al., "Angiotensinconverting-enzyme 2 inhibits liver fibrosis in mice," Hepatology, vol. 50, no. 3, pp. 929-938, 2009.

[20] X. Cao, F. Yang, T. Shi et al., "Angiotensin-converting enzyme 2/angiotensin-(1-7)/Mas axis activates Akt signaling to ameliorate hepatic steatosis," Scientific Reports, vol. 6, article 21592, 2016.

[21] S. K. Mantena, A. L. King, K. K. Andringa, H. B. Eccleston, and S. M. Bailey, "Mitochondrial dysfunction and oxidative stress in the pathogenesis of alcohol- and obesity-induced fatty liver diseases," Free Radical Biology and Medicine, vol. 44, no. 7, pp. 1259-1272, 2008.

[22] Y. Sumida, E. Niki, Y. Naito, and T. Yoshikawa, "Involvement of free radicals and oxidative stress in NAFLD/NASH," Free Radical Research, vol. 47, no. 11, pp. 869-880, 2013.

[23] R. M. Touyz and A. M. Briones, "Reactive oxygen species and vascular biology: implications in human hypertension," Hypertension Research, vol. 34, no. 1, pp. 5-14, 2011.

[24] J. Folch, M. Lees, and G. H. Sloane Stanley, "A simple method for the isolation and purification of total lipides from animal tissues," The Journal of Biological Chemistry, vol. 226, no. 1, pp. 497-509, 1957. 
[25] H. Ohkawa, N. Ohishi, and K. Yagi, "Assay for lipid peroxides in animal tissues by thiobarbituric acid reaction," Analytical Biochemistry, vol. 95, no. 2, pp. 351-358, 1979.

[26] P. Xu, A. C. Costa-Goncalves, M. Todiras et al., "Endothelial dysfunction and elevated blood pressure in Mas gene-deleted mice," Hypertension, vol. 51, no. 2, pp. 574-580, 2008.

[27] M. M. Bradford, "A rapid and sensitive method for the quantitation of microgram quantities of protein utilizing the principle of protein-dye binding," Analytical Biochemistry, vol. 72, no. 1-2, pp. 248-254, 1976.

[28] K. J. Livak and T. D. Schmittgen, "Analysis of relative gene expression data using real-time quantitative PCR and the $2^{-\Delta \Delta C_{T}}$ method," Methods, vol. 25, no. 4, pp. 402-408, 2001.

[29] F. Sheedfar, M. M. Y. Sung, M. Aparicio-Vergara et al., "Increased hepatic CD36 expression with age is associated with enhanced susceptibility to nonalcoholic fatty liver disease," Aging, vol. 6, no. 4, pp. 281-295, 2014.

[30] M. E. Miquilena-Colina, E. Lima-Cabello, S. Sánchez-Campos et al., "Hepatic fatty acid translocase CD36 upregulation is associated with insulin resistance, hyperinsulinaemia and increased steatosis in non-alcoholic steatohepatitis and chronic hepatitis C," Gut, vol. 60, no. 10, pp. 1394-1402, 2011.

[31] R. D. Clugston, J. J. Yuen, Y. Hu et al., "CD36-deficient mice are resistant to alcohol- and high-carbohydrate-induced hepatic steatosis," Journal of Lipid Research, vol. 55, no. 2, pp. 239-246, 2014.

[32] F. Xu, Z. Gao, J. Zhang et al., "Lack of SIRT1 (mammalian sirtuin 1) activity leads to liver steatosis in the SIRT1+/- mice: a role of lipid mobilization and inflammation," Endocrinology, vol. 151, no. 6, pp. 2504-2514, 2010.

[33] Y. Cao, Y. Xue, L. Xue et al., "Hepatic menin recruits SIRT1 to control liver steatosis through histone deacetylation," Journal of Hepatology, vol. 59, no. 6, pp. 1299-1306, 2013.

[34] K. Kackstein, A. Teren, Y. Matsumoto et al., "Impact of angiotensin II on skeletal muscle metabolism and function in mice: contribution of IGF-1, Sirtuin-1 and PGC-1 $\alpha$," Acta Histochemica, vol. 115, no. 4, pp. 363-370, 2013.

[35] J. M. O. Andrade, F. D. O. Lemos, S. da Fonseca Pires et al., "Proteomic white adipose tissue analysis of obese mice fed with a high-fat diet and treated with oral angiotensin-(1-7)," Peptides, vol. 60, pp. 56-62, 2014.

[36] N. E. Clarke, N. D. Belyaev, D. W. Lambert, and A. J. Turner, "Epigenetic regulation of angiotensin-converting enzyme 2 (ACE2) by SIRT1 under conditions of cell energy stress," Clinical Science, vol. 126, no. 7, pp. 507-516, 2014.

[37] R.-H. Wang, H.-S. Kim, C. Xiao, X. Xu, O. Gavrilova, and C.X. Deng, "Hepatic Sirtl deficiency in mice impairs mTorc2/Akt signaling and results in hyperglycemia, oxidative damage, and insulin resistance," The Journal of Clinical Investigation, vol. 121, no. 11, pp. 4477-4490, 2011.

[38] X. G. Lei, J.-H. Zhu, W.-H. Cheng et al., "Paradoxical roles of antioxidant enzymes: basic mechanisms and health implications," Physiological Reviews, vol. 96, no. 1, pp. 307-364, 2016.

[39] M. D. Brand and T. C. Esteves, "Physiological functions of the mitochondrial uncoupling proteins UCP2 and UCP3," Cell Metabolism, vol. 2, no. 2, pp. 85-93, 2005.

[40] C. Fleury, M. Neverova, S. Collins et al., "Uncoupling protein2: a novel gene linked to obesity and hyperinsulinemia," Nature Genetics, vol. 15, no. 3, pp. 269-272, 1997.

[41] A. Ruiz-Ramírez, M. Chávez-Salgado, J. A. Peñeda-Flores, E. Zapata, F. Masso, and M. El-Hafidi, "High-sucrose diet increases ROS generation, FFA accumulation, UCP2 level, and proton leak in liver mitochondria," American Journal of Physiology-Endocrinology and Metabolism, vol. 301, no. 6, pp. E1198-E1207, 2011.

[42] A. Kuhla, C. Hettwer, M. D. Menger, and B. Vollmar, "Oxidative stress-associated rise of hepatic protein glycation increases inflammatory liver injury in uncoupling protein-2 deficient mice," Laboratory Investigation, vol. 90, no. 8, pp. 1189-1198, 2010.

[43] M. Zhou, A. Xu, P. K. H. Tam et al., "Upregulation of UCP2 by adiponectin: the involvement of mitochondrial superoxide and hnRNP K," PLoS ONE, vol. 7, no. 2, Article ID e32349, 2012.

[44] Y. Nabeshima, S. Tazuma, K. Kanno, H. Hyogo, and K. Chayama, "Deletion of angiotensin II type I receptor reduces hepatic steatosis," Journal of Hepatology, vol. 50, no. 6, pp. 12261235, 2009.

[45] A. Besse-Patin and J. L. Estall, "An Intimate relationship between ROS and insulin signalling: implications for antioxidant treatment of fatty liver disease," International Journal of Cell Biology, vol. 2014, Article ID 519153, 9 pages, 2014.

[46] X. Cao, F.-Y. Yang, Z. Xin, R.-R. Xie, and J.-K. Yang, "The ACE2/ Ang-(1-7)/Mas axis can inhibit hepatic insulin resistance," Molecular and Cellular Endocrinology, vol. 393, no. 1-2, pp. 3038, 2014.

[47] P. Montez, J. P. Vázquez-Medina, R. Rodríguez et al., “Angiotensin receptor blockade recovers hepatic UCP2 expression and aconitase and SDH activities and ameliorates hepatic oxidative damage in insulin resistant rats," Endocrinology, vol. 153, no. 12, pp. 5746-5759, 2012. 


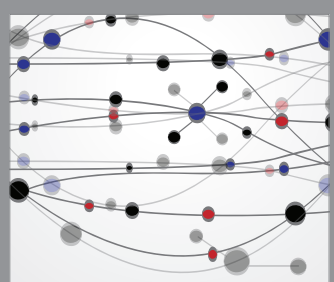

The Scientific World Journal
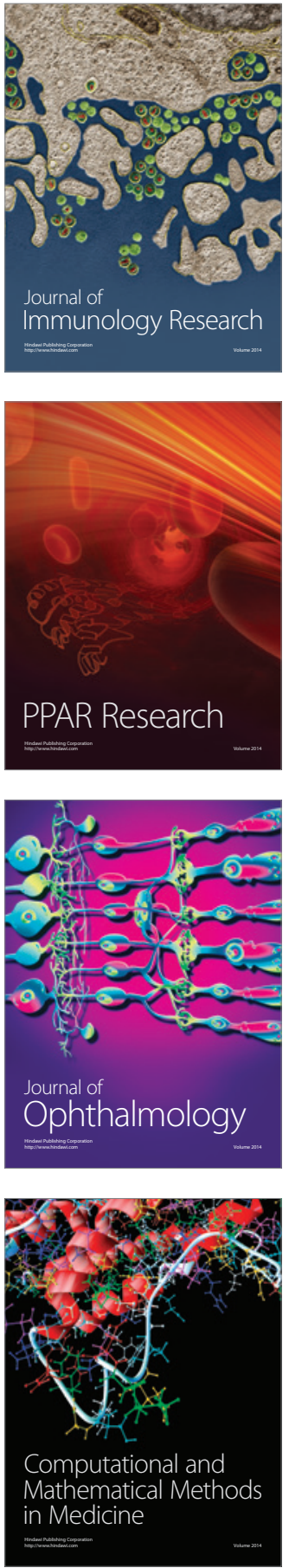

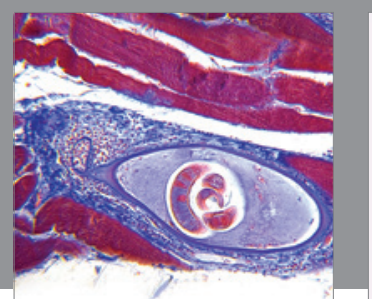

Gastroenterology Research and Practice

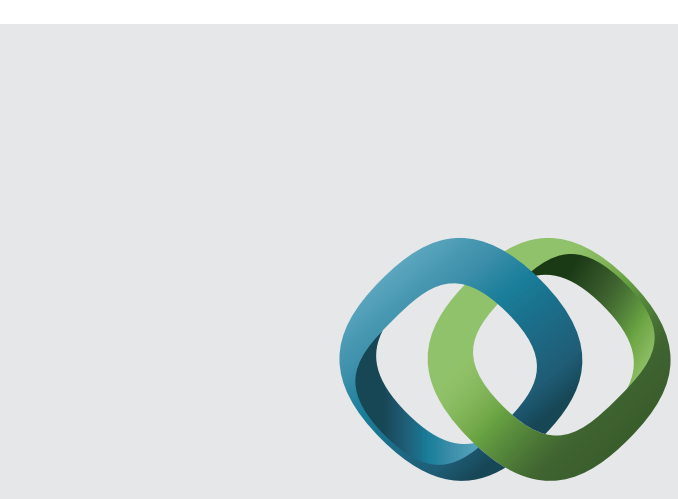

\section{Hindawi}

Submit your manuscripts at

http://www.hindawi.com
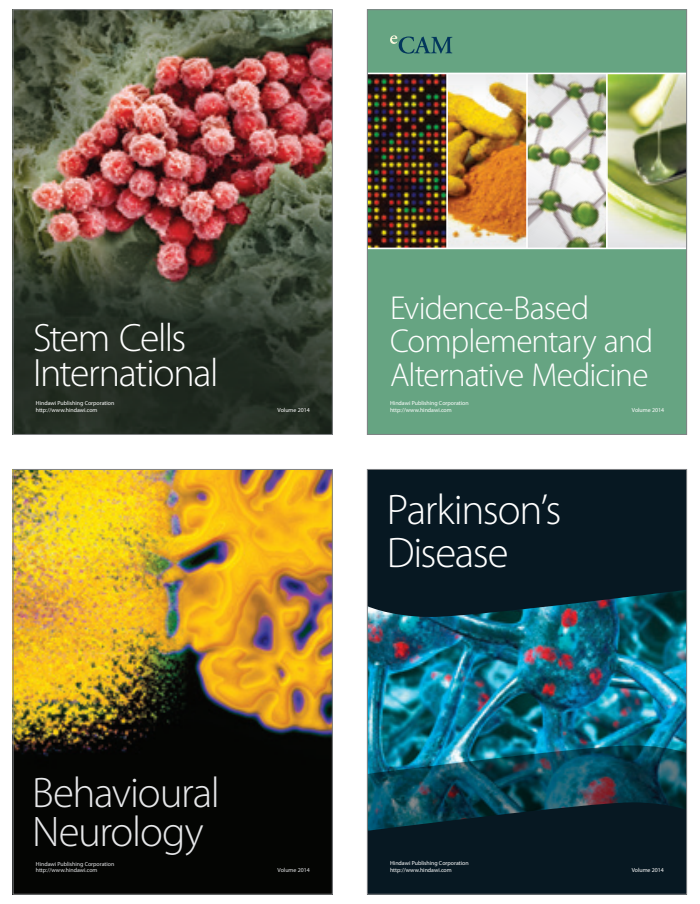
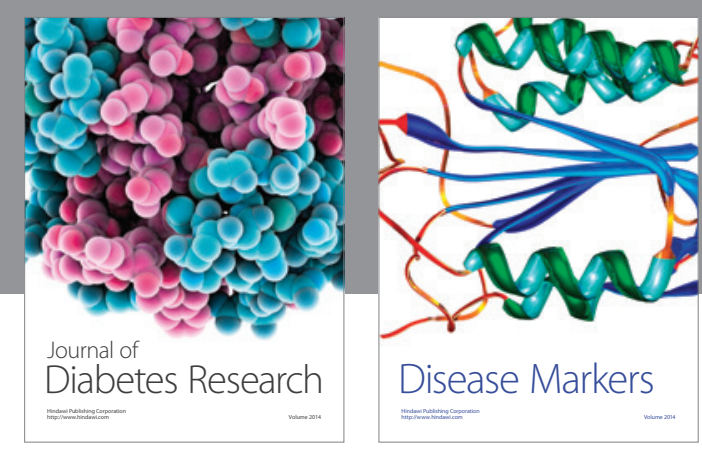

Disease Markers
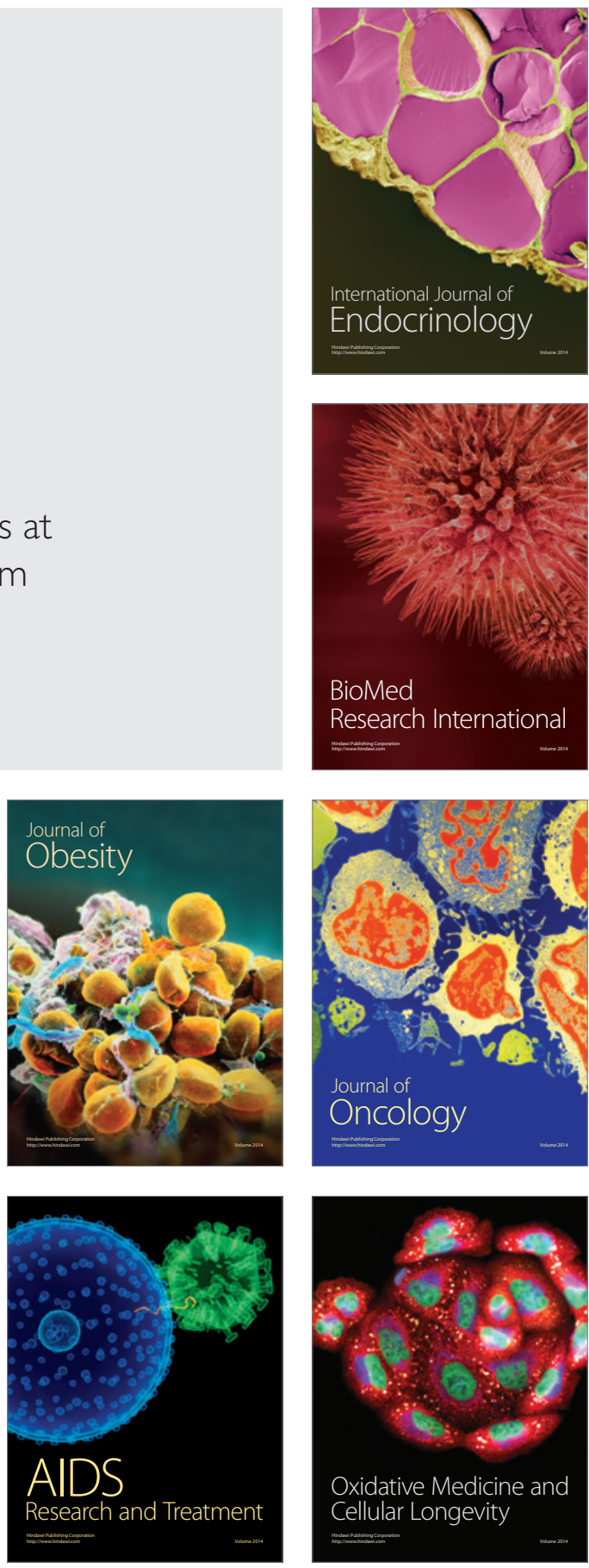